\title{
A model to simulate the haemodynamic effects of right heart pulsatile flow after modified Fontan procedure
}

\author{
Shuji Tamaki, Kouhei Kawazoe, Toshikatsu Yagihara, Toshio Abe
}

\begin{abstract}
The effect of pulsatile pulmonary flow after the modified Fontan procedure was examined in a model that simulated the right heart. An inlet overflow tank (preload), axial pulsatile pump, WindKessel model (afterload), and an outlet overflow tank were connected in series. The standard conditions were flow $2 \cdot 00$ $1 / \mathrm{min}$ with $12 \mathrm{~mm} \mathrm{Hg}$ preload pressure, 3.0 Wood units resistance, and an outlet overflow tank pressure at $6 \mathrm{~mm} \mathrm{Hg}$. The pump rate was set at 80 beats/min. The simulated pulmonary arterial pressure and pulmonary flow waves produced by this model closely resembled those obtained from patients who had undergone the modified Fontan procedure. All variables except the preload were fixed and changes in pulmonary flow were examined at preload pressures of 8, 12, 15 , and $17 \mathrm{~mm} \mathrm{Hg}$. As the peak pulmonary arterial pressure increased so did pulmonary flow, until it was greater than during the non-pulsatile state. Because the afterload of this model was fixed, this result suggests that there was a concomitant decrease in resistance.
\end{abstract}

This model indicates that pulsatile pulmonary blood flow is likely to have a beneficial efiect on the pulmonary circulation after the modified Fontan procedure.

After the modified Fontan procedure the right atrial and pulmonary arterial pressure waves, which are almost entirely a function of right

Accepted for publication 4 July 1991

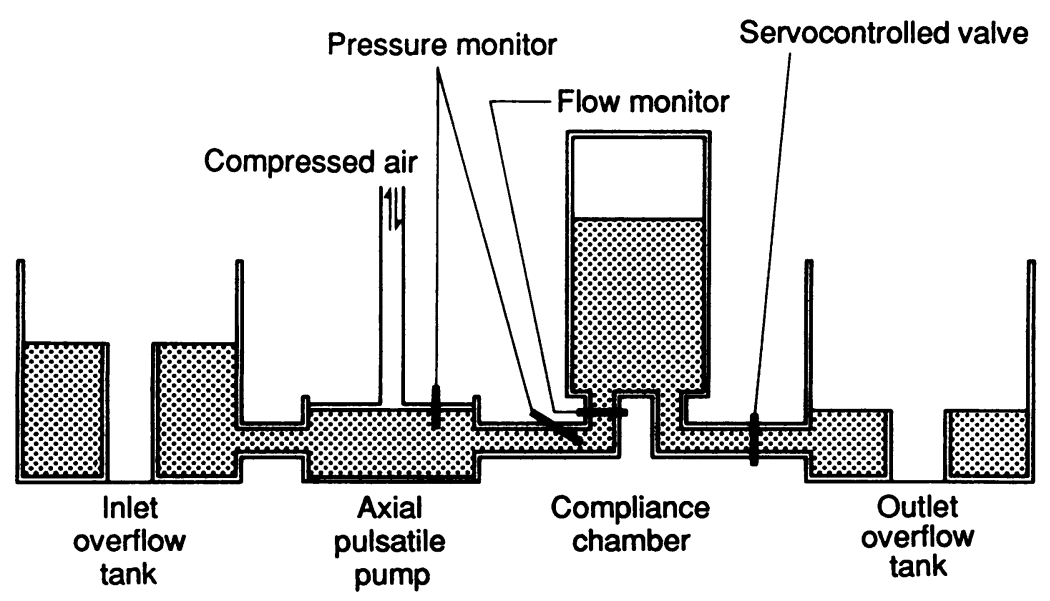

Figure 1 Simulation of the right heart after a modified Fontan procedure. The inlet overflow tank (preload), axial pulsatile pump, Wind-Kessel model (afterload), and the outlet overflow tank (left atrium) were connected in series and filled with water at $37^{\circ} \mathrm{C}$. atrial contraction and relaxation, have a characteristic configuration..$^{1-3}$ It has not known however, whether the pulsatile blood flow from the right heart has any effect on the pulmonary circulation. We studied this question in a model we constructed to simulate the right heart after the modified Fontan procedure.

\section{Method}

Figure 1 shows the model simulating the right heart after the modified Fontan procedure. The inlet overflow tank (preload), axial pulsatile pump, Wind-Kessel model (afterload), and the outlet overflow tank (left atrium) were connected in series and filled with water at $37^{\circ} \mathrm{C}$. A rise in the level of the water in the inlet overflow tank was prevented by an open cylinder. The height of this cylinder determined the preload. In this model the axial pulsatile pump had no prosthetic valves in either the inlet or outlet parts to better reproduce conditions present in the right atrium after the modified Fontan procedure. The Wind-Kessel model, which provided the afterload, was constructed of a compliance chamber and a servocontrolled valve. The compliance chamber was filled with air to one third of its total volume. ${ }^{4}$ The standard conditions were established in a non-pulsatile state: flow was $2.00 \mathrm{l} / \mathrm{min}$ with a $12 \mathrm{~mm} \mathrm{Hg}$ preload, the afterload was 3.0 Wood units, and the outlet overflow tank pressure was $6 \mathrm{~mm} \mathrm{Hg}$. Afterload and outlet overflow tank pressures were fixed throughout the experiment. The pump was set at a rate of 80 beats $/ \mathrm{min}$. Under standard conditions this model produced pulmonary arterial pressures and pulmonary flow waves that resembled those recorded in a patient who had undergone the modified Fontan procedure (fig 2). The driving pressure, systolic fraction, and the vacuum were adjusted (while the standard conditions were maintained) to create a pulsatile flow that produced graduated increases peak pulmonary arterial pressures to values $1 \mathrm{~mm} \mathrm{Hg}$ greater than the preload. This was done to examine the changes generated in the pulmonary flow waves. The same manipulations were performed at the other preload values of 8,15 , and $17 \mathrm{~mm} \mathrm{Hg}$.

We used a Sharp control air driving pump (H-4000). All fluid filled catheters were connected to Gould P-50 pressure transducers. The flow rate was measured electromagnetically with a Nihonkouden MFV-2100 flowmeter and a FF-150T cannulating flow 

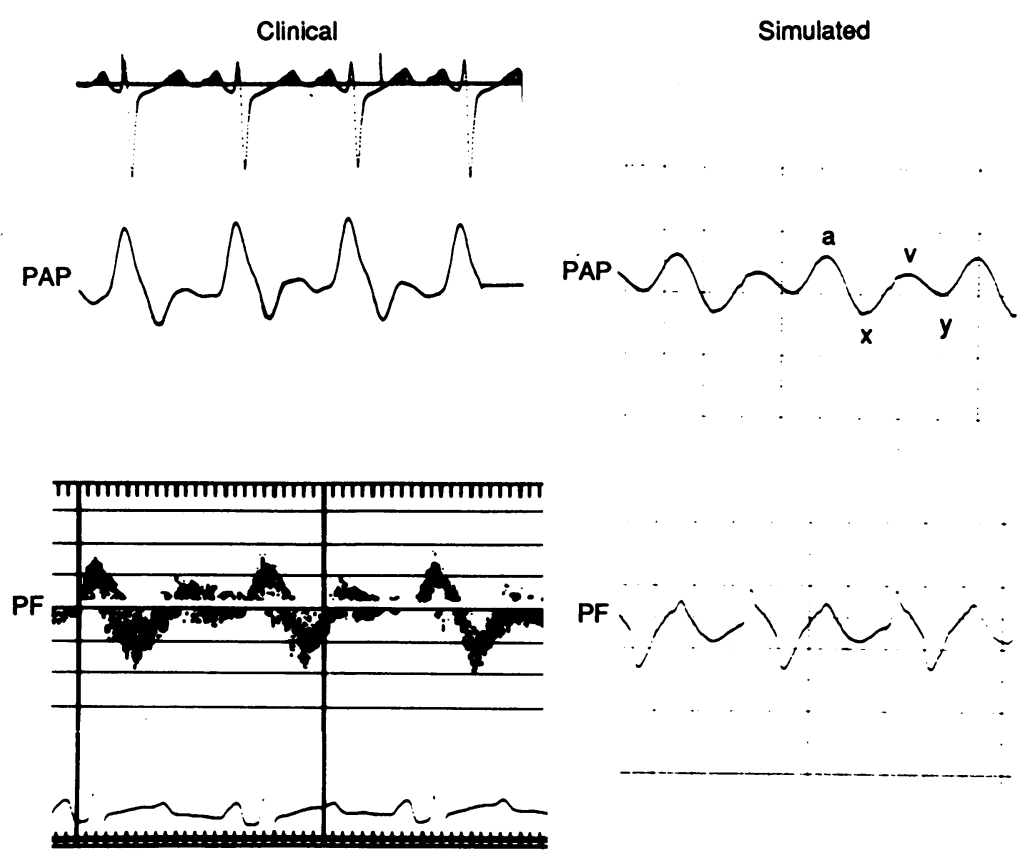

Figure 2 Clinical and simulated pulmonary arterial pressure $(P A P)$ and pulmonary flow (PF) waves. Clinical PF waves were recorded by Doppler echocardiography. Simulated PAP and PF waves closely resemble the clinical examples.

Figure 3 Non-pulsatile and pulsatile pulmonary flow $(P F)$, pulmonary arterial pressure $(P A P)$ and pump pressure (PP) waves under standard conditions: flow rate $2.00 \mathrm{l} / \mathrm{min}$, with

$12 \mathrm{~mm} \mathrm{Hg}$ preload, resistance, $3.0 \mathrm{Wood}$ units and an outlet overflow tank pressure of $6 \mathrm{~mm} \mathrm{Hg}$ in a non-pulsatile state. As the peak $P A P$ increased above the preload, the $P F$ increased from $2.00 \mathrm{l} / \mathrm{min}$ in the non-pulsatile state to a maximum of

$2.65 \mathrm{l} / \mathrm{min}$ at a peak $P A P$ of $19 \mathrm{~mm} \mathrm{Hg}$. transducer. Pressure and flow signals were recorded on a San-ei 361 eight channel polygraph.

\section{Results}

Under standard conditions, with a $12 \mathrm{~mm} \mathrm{Hg}$ preload, we simulated eight pulsatile flow patterns with peak pulmonary arterial pressures $1 \mathrm{~mm} \mathrm{Hg}$ greater than the preload-that is 13 , $14,15,16,17,18,19$, and $20 \mathrm{~mm} \mathrm{Hg}$ when the preload was $12 \mathrm{~mm} \mathrm{Hg}$. We recorded pump pressure, pulmonary flow, pulmonary arterial pressure, and waves at each pressure (fig 3). These waves closely resembled clinical tracings. As peak pulmonary arterial pressure became increasingly greater than the preload,

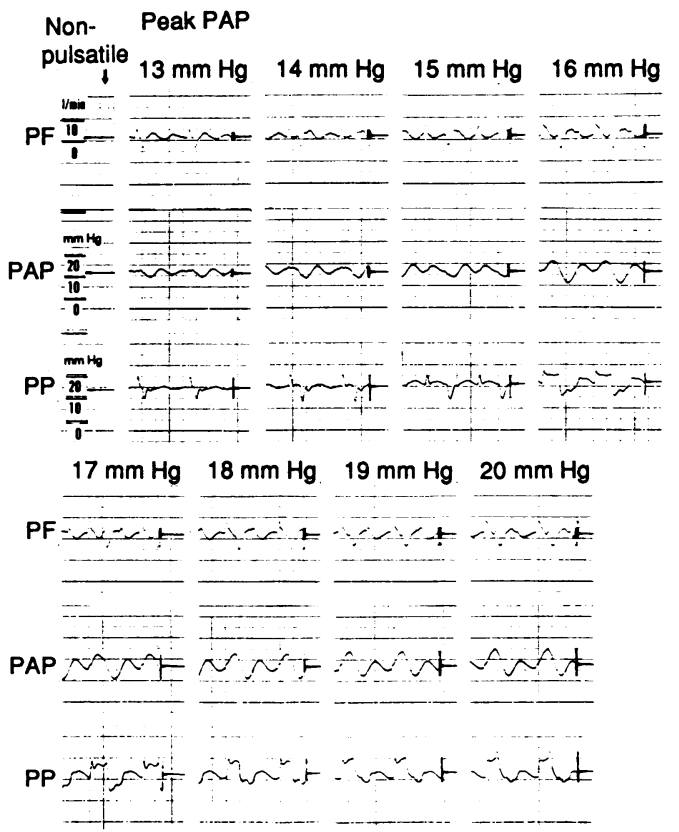

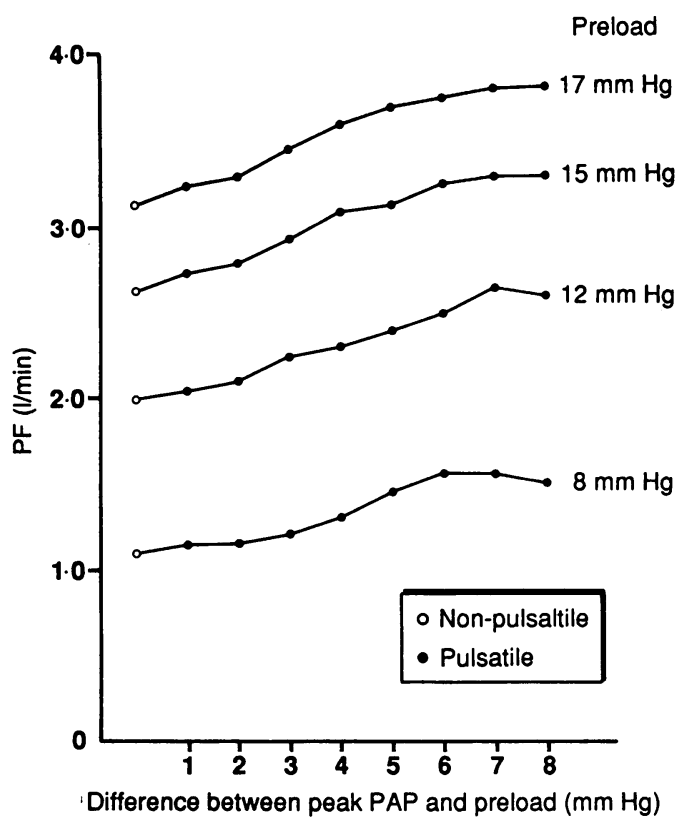

Figure 4 Changes in pulmonary flow (PF) examined at preloads of $8,12,15$, and $17 \mathrm{~mm} \mathrm{Hg}$ when all another variables remained constant. Each pulsatile flow pattern was produced by an increase in the peak pulmonary arterial pressure $(P A P)$ in $1 \mathrm{~mm} \mathrm{Hg}$ steps above the preload.

pulmonary flow increased from $2.00 \mathrm{l} / \mathrm{min}$ in the non-pulsatile state to a maximum of $2.65 \mathrm{l} /$ min at a peak pulmonary arterial pressure of $19 \mathrm{~mm} \mathrm{Hg}$ (fig 4). Changes in pulmonary flow were also seen when the preload was set at 8,15 , and $17 \mathrm{~mm} \mathrm{Hg}$ (fig 4) and all other standard conditions were held constant. At any given preload there was a corresponding pulmonary arterial pressure that produced the greatest pulmonary flow. For an $8 \mathrm{~mm} \mathrm{Hg}$ preload the largest pulmonary flow seen was $1.551 / \mathrm{min}$ at a peak pulmonary arterial pressure of $14 \mathrm{~mm} \mathrm{Hg}$. At a $15 \mathrm{~mm} \mathrm{Hg}$ preload and $22 \mathrm{~mm} \mathrm{Hg}$ peak pulmonary arterial pressure, pulmonary flow was $3.30 \mathrm{l} / \mathrm{min}$. With a preload of $17 \mathrm{~mm} \mathrm{Hg}$ and a peak pulmonary arterial pressure of $25 \mathrm{~mm} \mathrm{Hg}$, pulmonary flow was $3.80 \mathrm{l} / \mathrm{min}$. Peak flow rates under non-pulsatile conditions for preloads of $8 \mathrm{~mm} \mathrm{Hg}$, $15 \mathrm{~mm} \mathrm{Hg}$, and $17 \mathrm{~mm} \mathrm{Hg}$ were $1.101 / \mathrm{min}$, $2.65 \mathrm{l} / \mathrm{min}$, and $3.15 \mathrm{l} / \mathrm{min}$ respectively. Pulmonary flow when peak pulmonary arterial pressures were optimal was much greater than under non-pulsatile conditions.

\section{Discussion}

The results of clinical and experimental studies that examined the importance of atrial contraction in providing energy to the pulmonary circulation in patients after a modified Fontan procedure are conflicting. Yacoub reported that pulsatile pulmonary blood flow had a beneficial effect on gas exchange and affected the regulation of pulmonary vascular tone after this operation. ${ }^{5}$ Using a velocity transducer Nakazawa $e t$ al showed that atrial contraction enhanced flow into the pulmonary circulation. ${ }^{6}$ However, the results of several experimental ${ }^{78}$ and clinical $^{910}$ studies suggest that atrial 
contraction may not be essential for the maintenance of the pulmonary and systemic circulations. Thus the importance of pulsatile pulmonary blood flow from atrial contraction after the modified Fontan procedure remains controversial.

Changes in the right heart can be difficult to evaluate in vivo because changes in the left heart can affect the right heart. In the present right heart model we directly investigated the haemodynamic effects of pulsatile pulmonary flow. The axial pulsatile pump in this model had a contraction characteristic that was linearly related to the afterload. When Lau et al studied the instantaneous pressure-volume relation of the right atrium during isovolumic contraction in the canine heart they found a straight line relation between the end systolic pressure and volume. ${ }^{11}$ This suggests that the valveless axial pulsatile pump model may be able to simulate the haemodynamic effects of the right heart after the modified Fontan procedure. In fact, the pulmonary arterial pressure and pulmonary flow waves simulated in this model closely resemble the waveforms obtained from patients after the modified Fontan procedure. On the other hand, de Leval et al, using a similar system, reported that the introduction of pulsation predominantly increased the proximal venous pressure. ${ }^{12}$ The reasons for the discrepancy between their results and ours is not clear. However, their report did not specify the pulsatile conditions or include the pulmonary artery pressure tracings. We believe that it is important that the simulated pulmonary arterial pressure trace mimics a clinical one before meaningful conclusions can be drawn. We found that the pulmonary arterial pressure trace was affected by the pump driving pressure, fraction of systole, and the vacuum. In fact, in our model, suboptimal pulsatile conditions produced poor pulmonary flow, resulting in pulmonary arterial pressure tracings that did not resemble clinical ones. Such suboptimal conditions might contribute to increased back flow rather than to forward flow. Whether one of these factors or some other factor is responsible for the discrepancy between our results and those of de Leval et al is not clear and requires further study.

Nevertheless, in our model when the pulsatile conditions were optimised to produce a pulmonary arterial pressure trace that mimicked a clinical one, we found that as the peak pulmonary arterial pressure increased, pulmonary flow gradually increased until it was greater than during the non-pulsatile state. The resistance in this model is fixed by the non-elastic tube. So an increase in pulmonary flow with pulsation suggests that pulsation decreases the resistance. These results suggest that pulsatile pulmonary blood flow has a beneficial effect on the pulmonary circulation after the modified Fontan procedure.

1 Serratto M, Miller RA, Tatooles C, Ardekani R. Hemodynamic evaluation of Fontan operation in tricuspid atresia. Circulation 1976;54(suppl III):99-101.

2 Ross DN, Somerville J. Surgical correction of tricuspid atresia. Lancet 1973;i:845-9.

3 Sanders SP, Wright GB, Keane JF, Norwood WI, CastanSanders SP, Wright GB, Keane JF, Norwood WI, Castan-
eda AR. Clinical and hemodynamic results of Fontan operation for tricuspid atresia. Am J Cardiol 1982;49: 1733-9.

4 Umezu $\dot{M}$, Tomino T, Kawazoe $\mathrm{K}$, et al. Mechanical simulator for the evaluation of hemodynamic performance of artificial heart valves. Mechanics in Medicine and Biology, Digest of 2nd international conference 1980: 136-7.

5 Yacoub MH. Fontan's operation-are caval valves necessary? In: Anderson RH, Shinebourne EA, eds. Pediatric cardiology 1977. Edinburgh: Churchill Livingstone, 1977:581-8.

6 Nakazawa M, Nakanishi T, Okuda $H$, et al. Dynamics of right heart flow in patients after Fontan procedure. Circulation 1984;69:306-12.

7 Shemin RJ, Herrill WH, Pfeifer JS, Conkle DM, Morrow AG. Evaluation of right atrial-pulmonary arterial conduits for tricuspid atresia - experimental study. $J$ Thorac Cardiovasc Surg 1979;77:685-90.

8 Matsuda H, Kawashima Y, Takano H, Miyamoto K, Mori T. Experimental evaluation of atrial function in right T. Experimental evaluation of atrial function in right
atrium-pulmonary artery conduit operation for tricuspid atrium-pulmonary artery conduit operation for tricu
atresia. J Thorac Cardiovasc Surg 1981;81:762-7.

9 Behrendt DM, Rosenthal A. Cardiovascular status after repair by Fontan procedure. Ann Thorac Surg 1980;29: 322-30.

10 Janos GG, Gelfand MJ, Schwartz DC, Kaplan S. Postoperative evaluation of the Fontan procedure by radionuclide angiography. Am Heart J 1982;104:785-93.

11 Lau VK, Sagawa K, Suga H. Instantaneous pressurevolume relationship of right atrium during isovolumic contraction in canine heart. Am J Physiol 1979;236: H672-9.

12 de Leval MR, Kilner P, Gewillig M, Bull C. Total cavopulmonary connection: a logical alternative to atriopulmonary connection for complex Fontan operations. Experimental studies and early clinical experience. $J$ Thorac Cardiovasc Surg 1988;96:682-95. 